Tohoku J. Exp. Med., 2011, 224, 127-136

\title{
Short Sleep Duration and Irregular Bedtime Are Associated with Increased Behavioral Problems among Japanese Preschool-Age Children
}

\author{
Yoko Komada, ${ }^{1,2}$ Takashi Abe, ${ }^{1,2}$ Isa Okajima, ${ }^{1,2}$ Shoichi Asaoka, ${ }^{1,2}$ \\ Noriko Matsuura, ${ }^{3}$ Akira Usui, ${ }^{2,4}$ Shuichiro Shirakawa ${ }^{5}$ and Yuichi Inoue ${ }^{1,2}$ \\ ${ }^{1}$ Department of Somnology, Tokyo Medical University, Tokyo, Japan \\ ${ }^{2}$ Japan Somnology Center, Neuropsychiatric Research Institute, Tokyo, Japan \\ ${ }^{3}$ S\&A Associates, Inc., Tokyo, Japan \\ ${ }^{4}$ Faculty of Health Science Technology, Bunkyo Gakuin University, Tokyo, Japan \\ ${ }^{5}$ National Institute of Mental Health, National Center of Neurology and Psychiatry, Tokyo, Japan
}

\begin{abstract}
Sleep problems are known to be risk factors for subsequent emotional and behavioral difficulties in childhood and adolescence. To date, there has been no study investigating the relationships between sleep habits and behavioral problems in a large nonclinical sample of preschool age children. The aim of this study was to examine these relationships and factors associated with the sleep habits of preschool age ( 2 to 5 year old) children. Their mothers $(n=1,746)$ completed a multiple-choice questionnaire about the sleep habits and behavior problems of their children, as well as their own sleep habits and working hours at Tokyo metropolitan public nursery schools. The short sleep duration group showed significantly higher aggressive scores than the long sleep duration group among 2- to 3-year-old children, and the irregular bedtime group showed significantly higher aggressive and attention problem scores than the regular bedtime group among 4- to 5-year-old children. Univariate and multivariate logistic regression analyses revealed that children's late bedtime was associated with their mother's late waking-up time, and late schedule of both the mother's leaving and returning home. This study recognized an association between behavioral problems and poor sleep habits among preschool-age children. It is important for children to sleep regularly and adequately in order to decrease their behavior problems. In conclusion, appropriate management of children's sleep by their mothers is necessary for promoting sleep-related health of children.
\end{abstract}

Keywords: behavior problems; child; child behavior checklist; parents; sleep habits

Tohoku J. Exp. Med., 2011, 224 (2), 127-136. ㅇ 2011 Tohoku University Medical Press

Nocturnal sleep onset has become later and sleep duration has been progressively shortened in the last few decades (Aldrich 2003). Chronic insufficient sleep and sleep loss are common problems in modern industrial societies because annual work hours have become extended and a larger number of people are engaged in shift-work compared with the past (Aldrich 2003). Consistent with these trends in adults, bedtime has become progressively delayed, and sleep duration shortened among adolescents and children in industrial countries (Kohyama et al. 2002; Gangwisch et al. 2010; Asaoka et al. 2010). Studies conducted in a suburban area of Tokyo showed that the proportion of 3-year-old children going to bed at $10 \mathrm{PM}$ or later increased from $22 \%$ in 1980 to $50 \%$ in 2000 (Okawa and Uchiyama 1998; Kohyama et al. 2002).

Sleep plays an important role in children's develop- ment (Gregory and O'Connor 2002; Roberts et al. 2002). Sleep problems are risk factors for subsequent emotional and behavioral difficulties in childhood and adolescence (Gregory and O'Connor 2002; Roberts et al. 2002; Gregory et al. 2008). Short sleep duration and sleep disturbance are associated with higher scores of emotional lability in school-age children (Rosen et al. 2004; Nixon et al. 2008). Several other groups have shown reduced attention, impaired school performance, and hyperactivity in schoolage children caused by sleep disorders (Owens et al. 1998; Gottlieb et al. 2004). These findings demonstrate the association between sleep disorders and behavioral difficulties (Breslau et al. 1996; Gregory and O'Connor 2002; Roberts et al. 2002).

Several studies have also been performed on younger children. The association between sleep problems, espe-

Received February 7, 2011; revision accepted for publication May 16, 2011. doi: 10.1620/tjem.224.127

Correspondence: Yoko Komada, Ph.D., Department of Somnology, Tokyo Medical University, 6-7-1 Nishishinjuku, Shinjuku-ku,

Tokyo, Japan.

e-mail: ykoma@tokyo-med.ac.jp 
cially night waking and settling problems, and behavior problems was found in preschool age children (Richman et al. 1982). A correlation between toddlers' sleep $(n=31$; mean age: 18.5 months, range: 11 to 27 months) and temperament reported by mothers, especially between shorter sleep duration and less adaptability, has also been found (Scher et al. 1992). Atkinson et al. (1995) reported that toddlers with sleep problems such as night awakening had more difficulty with temperament. Bates et al. (2002) measured 4- to 5-year-old children's sleep patterns and their adjustment to the preschool environment among a predominantly low-income, community sample $(n=200)$, and found that disrupted sleep patterns predicted less optimal adjustment. In short, sleep problems are associated with not only adjustment problems in school-age children but also dysfunction of temperament and adjustment in preschool-age children. However, the samples in the papers referenced above were small in number. So far, there has been no study investigating the relationship between sleep habits and behavioral problems that have a profound impact on school adjustment (de Paul and Arruabarrena 1995; Davies et al. 2008) in a large nonclinical sample of preschool-age children. It could be hypothesized that behavioral problems such as lack of attention, aggressive behavior, and depression/anxiety are linked to deterioration of sleep habits. This study set out to clarify this hypothesis, focusing on preschool-age children.

Sleep habits and sleep behavior in children are influenced by many factors; e.g., biological, psychological, cultural, social, and family factors (Stores 1999; Liu et al. 2003; Komada et al. 2009). A recent study suggested that parents have a significant influence on the time of sleep onset and sleep maintenance for young children, with significant differences in parenting behaviors across cultural groups (Mindell et al. 2010). Among children who are predominantly Caucasian, the most common behavior occurring at bedtime is falling asleep independently in their own bed $(57 \%)$, but the rate is clearly lower $(4 \%)$ in children living in predominantly Asian regions (Mindell et al. 2010). Our previous study showed that parents of 1 - to 5-year-old children with evening irregular sleep had significantly more irregular sleep habits than parents of children with morning regular sleep (Komada et al. 2009).

These findings suggest that the sleep habits of children, especially in Asian regions, are strongly influenced by those of their parents. Considering this, another aim of our study was to elucidate whether sleep habits and working hours of parents influence the sleep habits of children, such as sleep duration and bedtime of preschool-age children.

\section{Methods}

\section{Subjects and procedure}

A questionnaire survey was conducted from June to August 2007 among 40 randomly selected public nursery schools in Minato, Shibuya, and Koto Wards all of which are located in Tokyo. Public nursery schools in Japan are intended for children of parents who are engaged in regular work. Except for Sundays and holidays, the nursery schools open from early morning (7:24 $\pm 0: 08$, mean \pm S.D. $)$ till evening (18:25 $\pm 0: 07)$, and offer overtime childcare till night (19:44 $\pm 0: 30$ ). Nursery hours are individually determined based on the commuting time and working schedule of parents. The nursery schools routinely set a nap schedule for children in the afternoon, based on the advice of the Ministry of Health, Labor, and Welfare. The average nap duration in nursery schools is 2 hours for 2- to 3 -year-old children and 1.5 hours for 4 - to 5 -year-old children. The subjects targeted in this study were mothers of children who belonged to 2- to 5-year-old children classes; 0 - to 1-year-old children classes were not targeted in this study, because the Child Behavior Check List (Achenbach 1991, 1992) we used in this study, as described later, is indicated for children aged 2 years or over. In this study, all participants were mothers, since the main childcare provider in the family is predominantly the mother in Japan (Fujimi and Nishino 2009). After thorough explanation of the purposes of this survey, mothers of 1746 children $(43.1 \%$ girls $)$ gave their written informed consent to take part in this investigation. Data on age, income, and educational background of parents were not obtained because of privacy-protection considerations. The nursery staff then gave the questionnaires to mothers, and retrieved them within 10 days. The study was approved by the ethics committee of the Neuropsychiatric Research Institute.

\section{Measures}

The main components of questionnaire items were as follows: (1) Sleep habits of children; (2) Child Behavior Check List; (3) Pittsburgh Sleep Quality Index (PSQI) (Buysse et al. 1989; Doi et al. 2000); (4) Parental Bonding Instrument (PBI) (Parker 1979); (5) Information regarding parents' daily life schedule. Mothers answered numerically or completed the multiple-choice questions about the following categories.

(1) Sleep habits of children over a recent typical month: Children's bedtime, waking-up time, sleep duration, bedtime regularity, sleep latency, number of episodes of waking up after bedtime on both weekdays and weekends were answered numerically. Questions about bedtime regularity had four possible categories (i.e., regular, moderately regular, moderately irregular, and irregular).

(2) Child Behavior Check List (CBCL): We used an international standardized method, a CBCL validated Japanese version for 2to 3-year old children (Achenbach 1992; Nakata et al. 1999) and for 4- to 18-year-old children (Achenbach 1991; Itani et al. 2001), to evaluate attention problems, aggressive behavior, and the anxious/ depressed category in children (Achenbach 1991, 1992). Subjects answered each question by selecting one of three choices of answers (i.e., not true, somewhat or sometimes true, and very true or often true). It has been previously identified that the higher the score, the greater the likelihood of problematic behavior in that scale (Achenbach 1991, 1992).

(3) Pittsburgh Sleep Quality Index (PSQI): We used the validated Japanese version of the PSQI in order to evaluate the mothers' sleep disturbance/problems i.e. difficulties falling asleep, initiating sleep, and maintaining sleep (Buysse et al. 1989; Doi et al. 2000). The Japanese version of the PSQI was developed by Doi et al. (2000), and a mean score for each component in both their control group and primary insomnia was indicated in their report (Doi et al. 2000). The PSQI included sub-items evaluating sleep quality (C1), sleep latency (C2), sleep duration (C3), habitual sleep efficiency (C4), sleep disturbance (C5), use of sleeping medication (C6), and daytime dysfunction 
(C7). The cut-off score of PSQI for insomnia was already determined to be 5.5 points (Doi et al. 2000). Therefore, in this study, responders with PSQI scores of 6 or higher were considered as poor sleeper.

(4) Parental Bonding Instrument (PBI): PBI assesses parental attitude toward child rearing (Parker 1979). It consists of 25 questions categorized into 2 scales: (a) care and (b) overprotection. Care (tapping into affection and warmth) is measured with 12 items such as "I speak to my child in a warm and friendly voice," and overprotection is measured with 13 items such as "I try to control everything my child does." Subjects answered each question by selecting 1 of 4 choices (i.e., very true, moderately true, moderately untrue, and very untrue).

(5) Information regarding daily life schedule: We asked about the parents' usual time of both leaving and returning home.

\section{Data analyses}

At first, we plotted the data of the relationship between bedtime on weekdays and the T score of behavioral problems. Pearson's simple correlation coefficient was used to assess the relationships. In addition, we investigated the relationship between children's sleep habits and behavioral problems. For the analysis, bedtime was divided into the early and late groups by the median value (2- to 3-year-old children: 21:40; 4- to 5-year-old children: 22:00). Sleep duration was also divided into short and long groups by the median value (2- to 3-year-old children: $9.5 \mathrm{~h}$; 4- to 5-year-old children: 9.3 h). Bedtime regularity was divided into regular and irregular groups based on the mothers' answers. Children with regular or moderately regular bedtime were classified as regular and the other was irregular. Scores of three subscale items of the CBCL; attention problems, aggressive behavior, and the anxious/depressed category; were compared between the 2 respective groups of the above sleep habits categories. Comparisons between two groups were performed by Student's $t$ test.

Secondly, factors associated with the sleep habits of children were examined by a series of logistic regression analyses. All variables were initially examined in univariate models. To control for confounding factors and to determine the main correlates, we then performed multivariate logistic regression analyses for all variables that showed a significant correlation in univariate models. Statistical tests of the regression estimated odds ratios (ORs) were based on Wald statistics. Odds ratios and their $95 \%$ confidence intervals (CIs) were presented to show the association.

All statistical analyses were conducted on SPSS version 11.5.1J software for Windows (SPSS Inc., Chicago, IL, USA), and a $p$ value of less than 0.01 was considered to indicate a statistically significant difference.

\section{Results}

A total of 2,682 eligible children whose mothers were requested to participate, mothers of 1,746 children (2- to 3-year-old classes: $n=905$; 4 - to 5-year-old classes: $n=$ 841 ) consented to take part in this study and completed the questionnaires (response rate $=65.1 \%$ ). The collection rate in 2- to 3-year-old children classes was significantly higher than that in 4 - to 5-year-old children classes $(68.5 \%$ vs 61.8 $\left.\%, \chi^{2}(1)=13.5, p<0.01\right)$. More mothers of boys agreed to participate than those of girls (mothers of boys, $56.9 \%$; mothers of girls, $43.1 \%$ ). Average $\mathrm{T}$ score \pm standard deviation (S.D.) of the 3 scales of the CBCL, i.e., attention problems, aggressive behavior, and the anxious/depressed category, were $55.0 \pm 8.0,56.4 \pm 7.9$, and $56.5 \pm 7.2$, respectively. The average PSQI score \pm s.D. of the mothers was $4.8 \pm 2.7$. Mean scores \pm S.D. for care and overprotection on the PBI were $41.3 \pm 4.3$ and $24.0 \pm 4.5$, respectively.

\section{Sleep habits}

Table 1 shows the sleep habits of children in both 2- to 3-year-old classes and 4- to 5-year-old classes on weekdays and on weekends, respectively. Average bedtime on weekdays was 21:41 in 2- to 3-year-old classes, and 21:51 in 4to 5-year-old classes. On weekends, children went to bed about 10 min later, and woke up about 30 min later than on weekdays. The difference in sleep length between weekdays and weekends was 18 minutes in 2- to 3-year-old classes and 16 minutes in 4 - to 5-year-old classes. The number of children whose bedtime regularity was "irregular" or "moderately irregular" was 170 of 900 (18.9\%) in 2to 3 -year-old classes, and 175 of $832(21.0 \%)$ in 4 - to 5-year-old classes.

Average sleep onset time, wakeup-time, and nocturnal sleep length of mothers were 23:20 $\pm 1: 17,6: 26 \pm 0: 50$, and $6: 43 \pm 1: 09$, respectively. Average time of leaving home and returning home were $8: 36 \pm 0: 55$ and $18: 15 \pm 1: 21$ for mothers, and 8:22 $\pm 1: 48$ and $21: 33 \pm 2: 32$ for fathers, respectively.

\section{Effects of sleep habits on behavior problems}

Relationship of the $\mathrm{T}$ score of attention problem and

Table 1. Sleep habits of children in both 2- to 3-year-old classes and 4- to 5-year-old classes.

\begin{tabular}{lcccccc}
\hline & \multicolumn{3}{c}{ 2- to 3-year-old class } & \multicolumn{3}{c}{ 4- to 5-year-old class } \\
\cline { 2 - 7 } & Mean & SD & Range & Mean & SD & Range \\
\hline Sleep onset time (weekdays) & $21: 41$ & $0: 41$ & $19: 00-25: 00$ & $21: 51$ & $0: 44$ & $19: 00-24: 00$ \\
Sleep onset time (weekends) & $21: 55$ & $0: 46$ & $19: 00-25: 00$ & $22: 06$ & $0: 48$ & $18: 30-24: 30$ \\
Wake-up time (weekdays) & $7: 06$ & $0: 35$ & $5: 20-9: 00$ & $7: 11$ & $0: 34$ & $5: 50-9: 50$ \\
Wake-up time (weekends) & $7: 38$ & $0: 51$ & $5: 30-13: 00$ & $7: 42$ & $0: 50$ & $6: 00-11: 30$ \\
Nocturnal sleep length (weekdays) & $9: 25$ & $0: 38$ & $7: 10-12: 00$ & $9: 19$ & $0: 39$ & $7: 20-12: 00$ \\
Nocturnal sleep length (weekends) & $9: 43$ & $0: 46$ & $6: 00-13: 00$ & $9: 35$ & $0: 45$ & $7: 00-12: 30$ \\
Difference in sleep length between Weekday and weekend & $0: 18$ & $0: 42$ & $-3: 00-4: 00$ & $0: 16$ & $0: 46$ & $-3: 00-4: 00$ \\
\hline
\end{tabular}



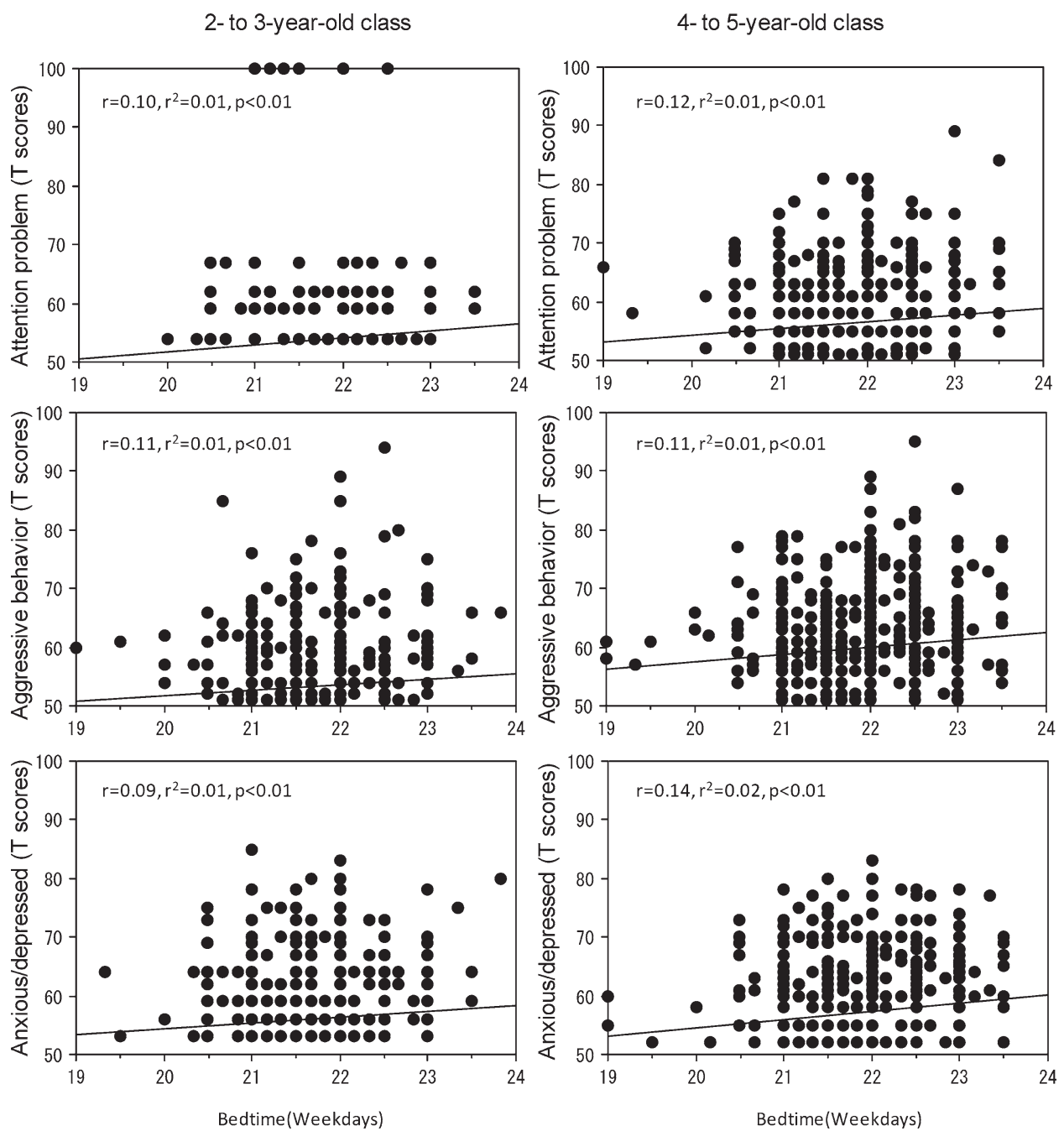

Fig. 1. Correlation between bedtime on weekdays and T score of the attention problem, aggressive behavior, and anxious/ depressed.

bedtime on weekdays are illustrated in Fig. 1. The standardized regression coefficients between bedtime and attention problem among 2- to 3-year-old children and 4- to 5 -year-old children were $0.10(p<0.01)$ and $0.12(p<$ 0.01 ), respectively.

We investigated the relationship between children's sleep habits and their behavioral problems (Fig. 2). T scores of three subscale items of the CBCL versions for 2to 3-year-old children and for subjects 4-18 years old; attention problems, aggressive behavior, and the anxious/ depressed category; were compared between the 2 groups (early and late bedtime groups: Fig. 2-(a) and (b); long and short sleep duration groups: Fig. 2-(c) and (d); regular and irregular bedtime groups: Fig. 2-(e) and (f)). As for sleep duration, the shorter group showed significantly higher scores of aggressive behavior problems than the longer group in 2- to 3-year-old children $[\mathrm{t}(873)=2.73, p<0.01$, Fig. 2-(c)]. As for bedtime regularity, the irregular group showed significantly higher attention problem and aggressive problem scores in 4- to 5-year-old children (attention problem: $\mathrm{t}(745)=2.74, p<0.01$; aggressive problem: $\mathrm{t}(719)=2.67, p<0.01$, Fig. 2-(f)).

\section{Associated factors for sleep habits of children}

We investigated the associated factors for sleep habits of preschool -age children (2- to 5-year-old children) including late bedtime on weekdays, short sleep duration on weekdays, and irregular bedtime. Univariate logistic regression analyses were performed on 9 independent variables: sleep habits of the mother, the PSQI and the PBI score of the mother, daily life schedule of respective parents. Among these variables, 4 items (i.e., bedtime, wakeup-time, time of both leaving and returning home of the mother) were significantly associated with late bedtime of children. To control for confounding factors and to determine the main correlates of late bedtime, the above 4 significant variables in the univariate models were subjected to multivariate analysis. Adjusted ORs and the 95\% CIs in the final model are shown in Table 2. Multivariate logistic regression analysis revealed that bedtime delay of 
2- to 3-year-old class

\section{(a) Weekday bedtime}

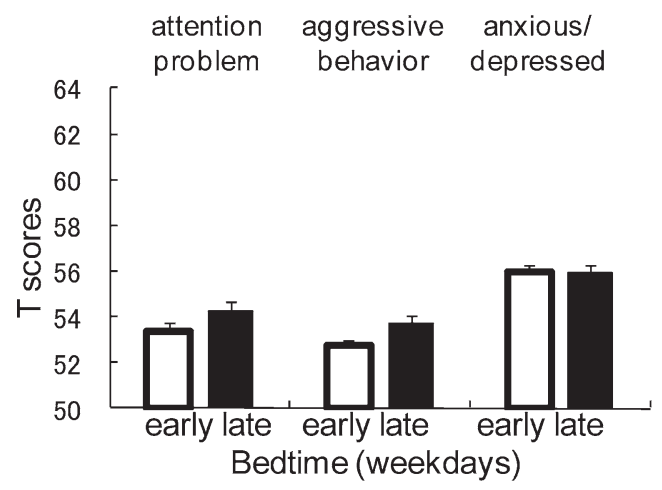

(c) Sleep duration

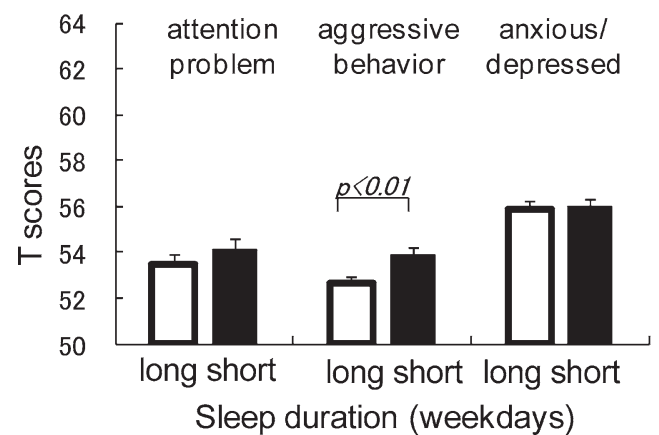

(e) Bedtime regularity

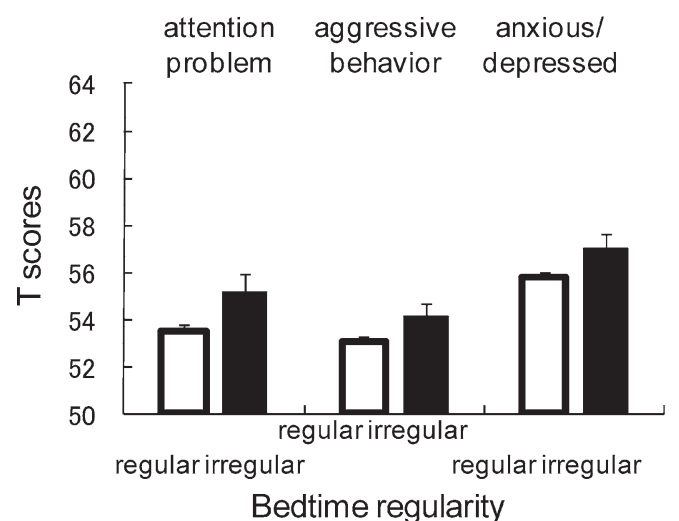

4- to 5-year-old class

(b) Weekday bedtime

attention aggressive anxious/

problem behavior depressed

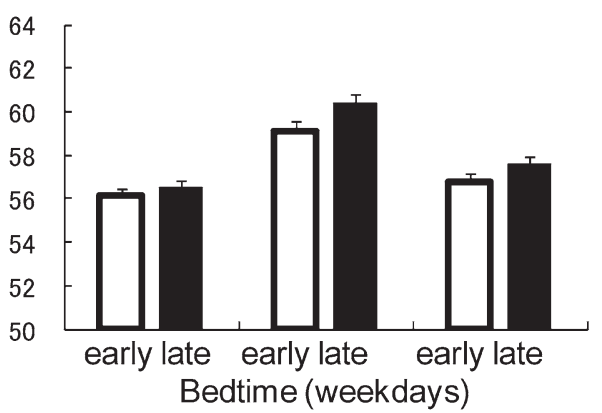

(d) Sleep duration

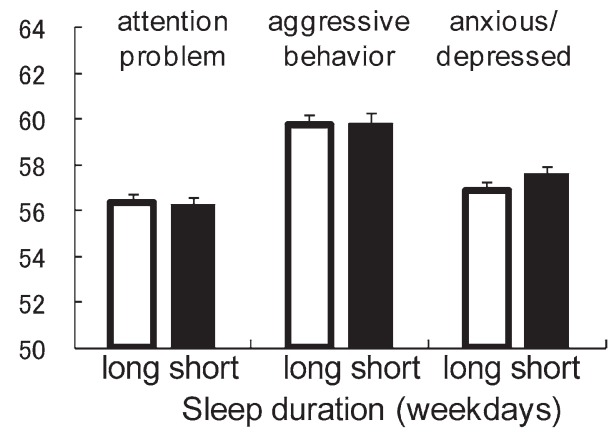

(f) Bedtime regularity

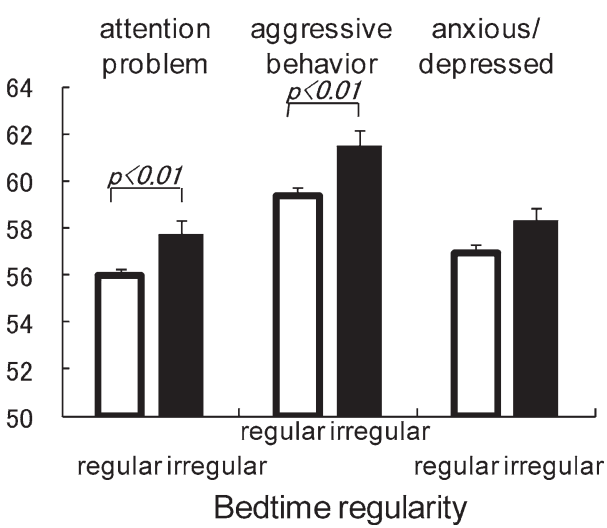

Fig. 2. Relationship between children's sleep habits and behavioral problems. Shown are the relationship between children's sleep habits and behavioral problems in 2- to 3-year-old children (left panels; a, c, and e) and 4-to 5-year-old children (right panels; b, d, and f.)

children was significantly associated with mothers' wakeuptime $(\mathrm{OR}=1.67,95 \% \mathrm{CI}: 1.29-2.17)$ as well as mothers' time of leaving and returning home $(\mathrm{OR}=1.58,95 \% \mathrm{CI}$ : $1.21-2.07, \mathrm{OR}=2.56,95 \% \mathrm{CI}: 2.00-3.28$, respectively). As for PSQI sub-items, there were no significantly associated factors identified by multivariate logistic regression analysis, although the univariate models revealed that bedtime delay of children was significantly associated with mother's sleep quality $(\mathrm{OR}=1.29,95 \% \mathrm{CI}$ : 1.12-1.48), sleep latency $(\mathrm{OR}=1.21,95 \% \mathrm{CI}: 1.08-1.35)$, and daytime dysfunction $(\mathrm{OR}=1.21,95 \% \mathrm{CI}: 1.07-1.36)$.
Five items (i.e., wake-up time, time of leaving and returning home of mother, and those of the father) among all the 9 variables were shown to be significantly associated with short sleep duration of children by univariate logistic regression analyses. Adjusted ORs and the 95\% CIs in the final model are shown in Table 3. Multivariate logistic regression analysis revealed that short sleep duration of children was significantly associated with wake-up time of mother $(\mathrm{OR}=0.71,95 \% \mathrm{CI}$ : $0.55-0.91)$, and time of both leaving and returning home of the mother $(\mathrm{OR}=0.61,95 \%$ CI: $0.47-0.79, \mathrm{OR}=1.84,95 \% \mathrm{CI}: 1.45-2.34$, respectively). 
Table 2. Results of univariate and multivariate logistic regression analyses of associated factors for children's late bedtime on weekdays.

\begin{tabular}{|c|c|c|c|c|c|c|c|}
\hline & \multirow{2}{*}{$\begin{array}{c}\text { Total } \\
n\end{array}$} & \multicolumn{2}{|c|}{ Stay up late*1 } & \multirow{2}{*}{$\begin{array}{l}\text { Univariate Relative Risk } \\
\qquad(95 \% \mathrm{CI}){ }^{* 2}\end{array}$} & \multirow[b]{2}{*}{$p$} & \multirow{2}{*}{$\begin{array}{l}\text { Multivariate Relative } \\
\text { Risk }\left(95 \% \text { CI } *^{2}\right.\end{array}$} & \multirow{2}{*}{$p$} \\
\hline & & $n$ & $\%$ & & & & \\
\hline \multicolumn{8}{|c|}{ Maternal factors } \\
\hline \multicolumn{8}{|c|}{ Bedtime $* 1$} \\
\hline Early & 729 & 336 & 46.1 & & & & \\
\hline Late & 967 & 544 & 56.3 & $1.50(1.24-1.83)$ & $<0.0001$ & & $n s$ \\
\hline \multicolumn{8}{|c|}{ Wakeup-time $* 1$} \\
\hline Early & 745 & 321 & 43.1 & & & & \\
\hline Late & 955 & 558 & 58.4 & $1.86(1.53-2.26)$ & $<0.0001$ & $1.67(1.29-2.17)$ & $<0.001$ \\
\hline \multicolumn{8}{|l|}{ PSQI $^{* 3}$} \\
\hline$<6$ & 1,149 & 575 & 50.0 & & & & \\
\hline$>=6$ & 516 & 290 & 56.2 & & $n s$ & & $n s$ \\
\hline \multicolumn{8}{|c|}{ Care score of PBI $* 1,4$} \\
\hline$>=42$ & 915 & 464 & 50.7 & & & & \\
\hline$<42$ & 734 & 392 & 53.4 & & $n s$ & & $n s$ \\
\hline \multicolumn{8}{|c|}{ Overprotection score of PBI $* 1,4$} \\
\hline$<24$ & 765 & 382 & 49.9 & & & & \\
\hline$>=24$ & 889 & 477 & 53.7 & & $n s$ & & $n s$ \\
\hline \multicolumn{8}{|c|}{ Time of leaving home $* 1$} \\
\hline Early & 701 & 318 & 45.4 & & & & \\
\hline Late & 913 & 513 & 56.2 & $1.54(1.26-1.88)$ & $<0.0001$ & $1.58(1.21-2.07)$ & $<0.001$ \\
\hline \multicolumn{8}{|c|}{ Time of returning home $* 1$} \\
\hline Early & 783 & 334 & 42.7 & & & & \\
\hline Late & 848 & 507 & 59.8 & $2.00(1.65-2.44)$ & $<0.0001$ & $2.56(2.00-3.28)$ & $<0.0001$ \\
\hline \multicolumn{8}{|c|}{$\underline{\text { Paternal factors }}$} \\
\hline \multicolumn{8}{|c|}{ Time of leaving home $* 1$} \\
\hline Early & 551 & 259 & 47.0 & & & & \\
\hline Late & 933 & 490 & 52.5 & & $n s$ & & $n s$ \\
\hline \multicolumn{8}{|c|}{ Time of returning home $* 1$} \\
\hline Early & 627 & 327 & 52.2 & & & & \\
\hline Late & 788 & 394 & 50.0 & & $n s$ & & $n s$ \\
\hline
\end{tabular}

${ }^{* 1}$ Categories were divided according to the median. ${ }^{* 2}$ Relative risks approximated to odds ratio. CI denotes confidence intervals.

${ }^{* 3}$ Pittsburgh sleep quality index. ${ }^{* 4}$ Parental bonding instrument.

As for mothers' PSQI sub-items, no items appeared as statistically significant factors for children's short sleep duration by both the univariate and multivariate logistic regression analyses.

With respect to irregular bedtime, 4 items (i.e., bedtime, wake-up time, the PSQI score, time of leaving home of the mother) among all the 9 variables exhibited significant association in univariate logistic regression analyses. Multivariate logistic regression analysis revealed that bedtime regularity of children was significantly associated with the mother's bedtime (OR $=1.58,95 \% \mathrm{CI}: 1.14-2.20)$, and time of leaving home $(\mathrm{OR}=1.59,95 \% \mathrm{CI}: 1.13-2.23$, Table 4). Among the PSQI sub-items, there were no significantly associated factors identified by multivariate logistic regression analysis, although the univariate models revealed that irregular bedtime of children was significantly associated with mother's sleep quality $(\mathrm{OR}=1.51,95 \% \mathrm{CI}$ : 1.27 $1.80)$, sleep latency ( $\mathrm{OR}=1.25,95 \% \mathrm{CI}: 1.10-1.42)$, use of sleeping medication (OR $=1.37,95 \% \mathrm{CI}: 1.14-1.64)$, and daytime dysfunction $(\mathrm{OR}=1.34,95 \% \mathrm{CI}$ : 1.16-1.54).

\section{Discussion}

We investigated the associations between children's sleep habits and behavioral problems using the CBCL questionnaire, which is an international standardized method to evaluate children's behavior problems. Several studies using the CBCL questionnaire have shown that children with sleep-disordered breathing showed behavioral problems including anxious/depressed mood (Aronen et al. 2009), aggressive behavior, and social problems (Lim et al. 2008). A preliminary study also using this questionnaire in Japan has revealed that late and irregular sleepers were 
Table 3. Results of univariate and multivariate logistic regression analyses of associated factors for children's short sleep duration on weekdays.

\begin{tabular}{|c|c|c|c|c|c|c|c|}
\hline & \multirow{2}{*}{$\begin{array}{c}\text { Total } \\
n\end{array}$} & \multicolumn{2}{|c|}{ Short sleep duration $*^{1}$} & \multirow{2}{*}{$\begin{array}{l}\text { Univariate Relative Risk } \\
\qquad(95 \% \mathrm{CI})^{* 2}\end{array}$} & \multirow{2}{*}{$p$} & \multirow{2}{*}{$\begin{array}{l}\text { Multivariate Relative } \\
\text { Risk }(95 \% \mathrm{CI}){ }^{2}\end{array}$} & \multirow{2}{*}{$p$} \\
\hline & & $n$ & $\%$ & & & & \\
\hline \multicolumn{8}{|c|}{ Maternal factors } \\
\hline \multicolumn{8}{|c|}{ Bedtime $* 1$} \\
\hline Early & 729 & 359 & 49.2 & & & & \\
\hline Late & 967 & 449 & 46.4 & & $n s$ & & $n s$ \\
\hline \multicolumn{8}{|c|}{ Wakeup-time $* 1$} \\
\hline Early & 745 & 422 & 56.6 & & & & \\
\hline Late & 955 & 387 & 40.5 & $0.52(0.43-0.63)$ & $<0.0001$ & $0.71(0.55-0.91)$ & $<0.01$ \\
\hline \multicolumn{8}{|l|}{ PSQI *3 } \\
\hline$<6$ & 1,149 & 561 & 48.8 & & & & \\
\hline$>=6$ & 516 & 236 & 45.7 & & $n s$ & & $n s$ \\
\hline \multicolumn{8}{|c|}{ Care score of PBI $* 1,4$} \\
\hline$>=42$ & 915 & 433 & 47.3 & & & & \\
\hline$<42$ & 734 & 357 & 48.6 & & $n s$ & & $n s$ \\
\hline \multicolumn{8}{|c|}{ Overprotection score of PBI $* 1,4$} \\
\hline$<24$ & 765 & 363 & 47.5 & & & & \\
\hline$>=24$ & 889 & 426 & 47.9 & & $n s$ & & $n s$ \\
\hline \multicolumn{8}{|c|}{ Time to leaving home $* 1$} \\
\hline Early & 701 & 417 & 59.5 & & & & \\
\hline Late & 913 & 366 & 40.1 & $0.45(0.37-0.55)$ & $<0.0001$ & $0.61(0.47-0.79)$ & $<0.001$ \\
\hline \multicolumn{8}{|c|}{ Time to returning home ${ }^{* 1}$} \\
\hline Early & 783 & 320 & 40.9 & & & & \\
\hline Late & 848 & 473 & 55.8 & $1.83(1.51-2.23)$ & $<0.0001$ & $1.84(1.45-2.34)$ & $<0.0001$ \\
\hline \multicolumn{8}{|c|}{$\underline{\text { Paternal factors }}$} \\
\hline \multicolumn{8}{|c|}{ Time to leaving home $* 1$} \\
\hline Early & 551 & 302 & 54.8 & & & & \\
\hline Late & 933 & 401 & 43.0 & $0.62(0.50-0.77)$ & $<0.0001$ & & $n s$ \\
\hline \multicolumn{8}{|c|}{ Time to returning home $* 1$} \\
\hline Early & 627 & 327 & 52.2 & & & & \\
\hline Late & 788 & 343 & 43.5 & $0.70(0.57-0.87)$ & $<0.01$ & & $n s$ \\
\hline
\end{tabular}

${ }^{* 1}$ Categories were divided according to the median. ${ }^{* 2}$ Relative risks approximated to odds ratio. CI denotes confidence intervals.

${ }^{* 3}$ Pittsburgh sleep quality index. ${ }^{* 4}$ Parental bonding instrument.

likely to show problematic behavior (Yokomaku et al. 2008). However, our study is the first to use a survey with sleep questionnaires and the CBCL focusing on a number of preschool-age children. Our results showed that poor sleep habits were significantly related to behavioral problems; short sleep duration and irregular bedtime were significantly related to elevated attention problem scores and aggressive problem scores, although the effects were limited.

Short sleep duration and sleep disturbance have been associated with higher emotional lability in school-age children (Nixon et al. 2008; Rosen et al. 2004). Another study has also shown reduced attention, impaired school performance, and hyperactivity in children with sleep disorders (Gottlieb et al. 2004). Our results indicate that behavioral problems, such as attention problems, aggressive behavior, and depression/anxiety, were associated with deterioration of sleep habits even among a nonclinical sample of preschool-age children, as we had hypothesized.

The current study showed that sleep habits of 2- to 5 -year-old children in Japan were poor; average bedtime on weeknights was later than 9:30 PM and average nocturnal sleep duration was less than 9.5 hours. Time in bed by parental report in a cohort of New Zealand Caucasian 7-year-old children was 10.9 hours (Nixon et al. 2008), which was similar to that reported in UK children (Gulliford et al. 1990). A U.S. national survey conducted in 2003 indicated that average bedtime on weeknights ranged from 8:44 PM at 2 years old to 8:58 PM at 5 years old, and the average sleep duration was 9.6 hours in 2- to 5-year-old children (National Sleep Foundation 2004). In comparison with these data, the results of our study demonstrated that sleep duration of the children was shorter, owing to the late bedtime. The nursery schools in this study routinely set a 
Table 4. Results of univariate and multivariate logistic regression analyses of associated factors for children's irregular bedtime.

\begin{tabular}{|c|c|c|c|c|c|c|c|}
\hline & \multirow{2}{*}{$\begin{array}{c}\text { Total } \\
n\end{array}$} & \multicolumn{2}{|c|}{ Irregular $* 1$} & \multirow{2}{*}{$\begin{array}{l}\text { Univariate Relative Risk } \\
\qquad(95 \% \mathrm{CI})^{* 2}\end{array}$} & \multirow{2}{*}{$p$} & \multirow{2}{*}{$\begin{array}{l}\text { Multivariate Relative Risk } \\
\qquad(95 \% \mathrm{CI}) * 2\end{array}$} & \multirow{2}{*}{$p$} \\
\hline & & $n$ & $\%$ & & & & \\
\hline \multicolumn{8}{|c|}{ Maternal factors } \\
\hline \multicolumn{8}{|c|}{ Bedtime $*^{2}$} \\
\hline Early & 729 & 103 & 14.1 & & & & \\
\hline Late & 967 & 228 & 23.6 & $1.86(1.44-2.41)$ & $<0.0001$ & $1.58(1.14-2.20)$ & $<0.01$ \\
\hline \multicolumn{8}{|c|}{ Wakeup-time ${ }^{* 2}$} \\
\hline Early & 745 & 103 & 13.8 & & & & \\
\hline Late & 955 & 228 & 23.9 & $1.96(1.51-2.53)$ & $<0.0001$ & & $n s$ \\
\hline \multicolumn{8}{|l|}{ PSQI *4 } \\
\hline$<6$ & 1,149 & 198 & 17.2 & & & & \\
\hline$>=6$ & 516 & 127 & 24.6 & $1.56(1.21-2.01)$ & $<0.001$ & & $n s$ \\
\hline \multicolumn{8}{|c|}{ Care score of PBI $* 2,5$} \\
\hline$>=42$ & 915 & 168 & 18.4 & & & & \\
\hline$<42$ & 734 & 151 & 20.6 & & $n s$ & & $n s$ \\
\hline \multicolumn{8}{|c|}{ Overprotection score of PBI $* 2,5$} \\
\hline$<24$ & 765 & 131 & 17.1 & & & & \\
\hline$>=24$ & 889 & 190 & 21.4 & & $n s$ & & $n s$ \\
\hline \multicolumn{8}{|c|}{ Time to leaving home $*^{2}$} \\
\hline Early & 701 & 103 & 14.7 & & & & \\
\hline Late & 913 & 209 & 22.9 & $1.72(1.33-2.23)$ & $<0.0001$ & $1.59(1.13-2.23)$ & $<0.01$ \\
\hline \multicolumn{8}{|c|}{ Time to returning home $* 2$} \\
\hline Early & 783 & 154 & 19.7 & & & & \\
\hline Late & 848 & 162 & 19.1 & & $n s$ & & $n s$ \\
\hline \multicolumn{8}{|c|}{ Paternal factors } \\
\hline \multicolumn{8}{|c|}{ Time to leaving home $*^{2}$} \\
\hline Early & 551 & 99 & 18.0 & & & & \\
\hline Late & 933 & 175 & 18.8 & & $n s$ & & $n s$ \\
\hline \multicolumn{8}{|c|}{ Time to returning home ${ }^{* 2}$} \\
\hline Early & 627 & 108 & 17.2 & & & & \\
\hline Late & 788 & 157 & 19.9 & & $n s$ & & $n s$ \\
\hline
\end{tabular}

${ }^{* 1}$ Mother's description of their child's bedtime regularity is "irregular" or "moderately irregular". *2 Categories were divided according to the median. ${ }^{* 3}$ Relative risks approximated to odds ratio. CI denotes confidence intervals. ${ }^{* 4}$ Pittsburgh sleep quality index. ${ }^{* 5}$ Parental bonding instrument.

nap schedule in the afternoon for children. The average nap duration in nursery schools was 2 hours for 2- to 3-year-old children and 1.5 hours for 4 - to 5-year-old children. Therefore, differences in napping behavior were not thought to have a definitive influence in the present study. However, the long nap duration, especially in older children, might partially contribute to the nocturnal bedtime delay.

The current study found no significant association between the scale scores of the PBI evaluating care and overprotection by mothers and children's sleep habits. Of note, however, are that the late bedtime, short sleep duration, and irregular bedtime of children appeared to depend on the mother's daily schedule (i.e., wake-up time and time of returning home). The father's daily schedule had little or no effect on children's sleep habits. Our previous study also showed that mothers' sleep habits have a stronger influence on their children's sleep than fathers' sleep habits (Komada et al. 2009). These findings are due to the fact that the mother is still the main caregiver in Japan, suggesting that children's sleep habits are influenced more by the mother's schedule rather than her philosophy about how the children should be raised, as evaluated by the PBI. Therefore, our results emphasize the need for social support for mothers so that their burden can be reduced. This situation is different from that seen in some Western countries. There are smaller numbers of preschool-age children who sleep independently in Asian countries, although the National Sleep Foundation advises that children of all ages should fall asleep independently (Mindell et al. 2009). Considering this, differences in the relationship between sleep habits of children and that of parents according to country are needed. 
The current study has several limitations. First, details on the characteristics of non-participants were not clarified. The data collection rate from the mothers of 2- to 3-yearold children was significantly higher than that from the mothers of 4- to 5-year-old children. The reason for this phenomenon is not clear. However, considering that the number of nursery staff in 2- to 3-year-old children class is more than that in 4- to 5-year-old children class (Japanese law, Child Welfare Act), there might be a closer connection between nursery staff and mothers, possibly contributing to the difference in collection rate. The reason why more mothers of boys agree to participate could not be clarified.

Secondly, although the sleep habits of children are affected by socio-cultural environments, socioeconomic, ethics of the family (Giannotti et al. 2005; Crosby et al. 2005), data on age, income, and educational background of parents were not obtained. Thus, the results should be interpreted with caution. Thirdly, no objective measures were applied to the data either on sleep habits or behavior problems. Furthermore, only 3 items of the CBCL (i.e., attention problems, aggressive behavior, and the anxious/ depressed category) were used in this study to estimate behavioral problems. However, as for sleep habits, it has been reported that there were overall similarities between actigraph sleep measures and mother-reported measures (Acebo et al. 2005). As for behavior problems, although the CBCL is widely used and well validated, assessment of behavior problems by other estimators has been recommended (Aronen et al. 2009). Further investigations of other variables about behavioral problems not only by mothers but also by nursery school teachers would be informative.

This study revealed a small but significant association between behavioral problems and poor sleep habits including short sleep duration and irregular bedtime among preschool-age nursery school children. Our results support the idea that it is necessary for preschool-age nursery school children to sleep regularly and adequately. The mother's work and daily schedule was regarded as a key to the sleep habits of Japanese children. The importance of appropriate limit-setting in cooperation with other family members should be emphasized so that we can protect children's sleep.

\section{Acknowledgments}

The authors are indebted to Professor J. Patrick Barron and Assistant Professor Edward F. Barroga of the Department of International Medical Communications of Tokyo Medical University for their re-review of this manuscript.

\section{Disclosure Statement}

This study was supported by a MEXT (Ministry of Education, Culture, Sports, Science and Technology) sponsored project.

\section{Conflict of Interest}

None of the authors have any conflicts of interest associated with this study.

\section{References}

Acebo, C., Sadeh, A., Seifer, R., Tzischinsky, O., Hafer, A. \& Carskadon, M.A. (2005) Sleep/wake patterns derived from activity monitoring and maternal report for healthy 1 - to 5-year-old children. Sleep, 28, 1568-1577.

Achenbach, T.M. (Ed.) (1991) Manual for the child behavior checklist/4-18 and 1992 profile, University of Vermont, Department of Psychiatry, Burlington VT.

Achenbach, T.M. (Ed.) (1992) Manual for the child behavior checklist/2-3 and 1991 profile, University of Vermont, Department of Psychiatry, Burlington VT.

Aldrich, M.S. (2003) In Sleep-Physiology, Investigatoins, and Medicine (Ed, Billiard, M.) Kluwer Academic/ Plenum Publishers, New York, pp. 341-346.

Aronen, E.T., Liukkonen, K., Simola, P., Virkkula, P., Uschakoff, A., Korkman, M., Kirjavainen, T. \& Pitkaranta, A. (2009) Mood is associated with snoring in preschool-aged children. $J$. Dev. Behav. Pediatr., 30, 107-114.

Asaoka, S., Komada, Y., Fukuda, K., Sugiura, T., Inoue, Y. \& Yamazaki, K. (2010) Exploring the daily activities associated with delayed bedtime of Japanese university students. Tohoku J. Exp. Med., 221, 245-249.

Atkinson, E., Vetere, A. \& Grayson, K. (1995) Sleep disruption in young children. The influence of temperament on the sleep patterns of pre-school children. Child Care Health Dev., 21, 233-246.

Bates, J.E., Viken, R.J., Alexander, D.B., Beyers, J. \& Stockton, L. (2002) Sleep and adjustment in preschool children: sleep diary reports by mothers relate to behavior reports by teachers. Child Dev., 73, 62-74.

Breslau, N., Roth, T., Rosenthal, L. \& Andreski, P. (1996) Sleep disturbance and psychiatric disorders: a longitudinal epidemiological study of young adults. Biol. Psychiatry, 39, 411-418.

Buysse, D.J., Reynolds, C.F. 3rd, Monk, T.H., Berman, S.R. \& Kupfer, D.J. (1989) The Pittsburgh Sleep Quality Index: a new instrument for psychiatric practice and research. Psychiatry Res., 28, 193-213.

Crosby, B., LeBourgeois, M.K. \& Harsh, J. (2005) Racial differences in reported napping and nocturnal sleep in 2- to 8-yearold children. Pediatrics, 115, 225-232.

Davies, P.T., Woitach, M.J., Winter, M.A. \& Cummings, E.M. (2008) Children's insecure representations of the interparental relationship and their school adjustment: the mediating role of attention difficulties. Child Dev., 79, 1570-1582.

de Paul, J. \& Arruabarrena, M.I. (1995) Behavior problems in school-aged physically abused and neglected children in Spain. Child Abuse Negl., 19, 409-418.

Doi, Y., Minowa, M., Uchiyama, M., Okawa, M., Kim, K., Shibui, K. \& Kamei, Y. (2000) Psychometric assessment of subjective sleep quality using the Japanese version of the Pittsburgh Sleep Quality Index (PSQI-J) in psychiatric disordered and control subjects. Psychiatry Res., 97, 165-172.

Fujimi, S. \& Nishino, M. (Eds.) (2009) Family patterns in contemporary Japan (in Japanese), Yuhikaku, Tokyo.

Gangwisch, J.E., Babiss, L.A., Malaspina, D., Turner, J.B., Zammit, G.K. \& Posner, K. (2010) Earlier parental set bedtimes as a protective factor against depression and suicidal ideation. Sleep, 33, 97-106.

Giannotti, F., Cortesi, F., Sebastiani, T. \& Vagnoni, C. (2005) Sleeping habits in Italian children and adolescents. Sleep Biol. Rhythms, 3, 15-21.

Gottlieb, D.J., Chase, C., Vezina, R.M., Heeren, T.C., Corwin, M.J., 
Auerbach, S.H., Weese-Mayer, D.E. \& Lesko, S.M. (2004) Sleep-disordered breathing symptoms are associated with poorer cognitive function in 5-year-old children. J. Pediatr., 145, $458-464$

Gregory, A.M. \& O'Connor, T.G. (2002) Sleep problems in childhood: a longitudinal study of developmental change and association with behavioral problems. J. Am. Acad. Child Adolesc. Psychiatry, 41, 964-971.

Gregory, A.M., Van der Ende, J., Willis, T.A. \& Verhulst, F.C. (2008) Parent-reported sleep problems during development and self-reported anxiety/depression, attention problems, and aggressive behavior later in life. Arch. Pediatr. Adolesc. Med., 162, 330-335.

Gulliford, M.C., Price, C.E., Rona, R.J. \& Chinn, S. (1990) Sleep habits and height at ages 5 to 11. Arch. Dis. Child., 65, 119122.

Itani, T., Kanbayashi, Y., Nakata, Y., Kita, M., Fujii, H., Kuramoto, H., Negishi, T., Tezyuka, M. \& Okada, A. (2001) Standardization of the Japanese version of the child behavior checklist/4-18 (in Japanese). Shoni No Seishin To Shinkei, 41, 243-252.

Kohyama, J., Shiiki, T., Ohinata-Sugimoto, J. \& Hasegawa, T. (2002) Potentially harmful sleep habits of 3-year-old children in Japan. J. Dev. Behav. Pediatr., 23, 67-70.

Komada, Y., Adachi, N., Matsuura, N., Mizuno, K., Hirose, K., Aritomi, R. \& Shirakawa, S. (2009) Irregular sleep habits of parents are associated with increased sleep problems and daytime sleepiness of children. Tohoku J. Exp. Med., 219, 85-89.

Lim, C.G., Ooi, Y.P., Fung, D.S., Mahendran, R. \& Kaur, A. (2008) Sleep disturbances in Singaporean children with attention deficit hyperactivity disorder. Ann. Acad. Med. Singapore, 37, 655-661.

Liu, X., Liu, L. \& Wang, R. (2003) Bed sharing, sleep habits, and sleep problems among Chinese school-aged children. Sleep, 26, 839-844.

Mindell, J.A., Meltzer, L.J., Carskadon, M.A. \& Chervin, R.D. (2009) Developmental aspects of sleep hygiene: findings from the 2004 National Sleep Foundation Sleep in America Poll. Sleep Med., 10, 771-779.

Mindell, J.A., Sadeh, A., Kohyama, J. \& How, T.H. (2010)
Parental behaviors and sleep outcomes in infants and toddlers: a cross-cultural comparison. Sleep Med., 11, 393-399.

Nakata, Y., Kambayashi, Y., Fukui, T., Fujii, H., Kita, M., Okada, A. \& Morioka, Y. (1999) Standardization of Japanese child behavioral checklist for age 2-3 (in Japanse). Shoni No Seishin To Shinkei, 39, 317-322.

National Sleep Foundation (2004) the 2004 Sleep in America Poll. www.sleepfoundation.org.

Nixon, G.M., Thompson, J.M., Han, D.Y., Becroft, D.M., Clark, P.M., Robinson, E., Waldie, K.E., Wild, C.J., Black, P.N. \& Mitchell, E.A. (2008) Short sleep duration in middle childhood: risk factors and consequences. Sleep, 31, 71-78.

Okawa, M. \& Uchiyama, M. (1998) In Normal and abnormal sleep (Eds, Okuma, T. and Miyamoto, T.) Nihon Hyouronsha, Tokyo, pp. 43-60.

Owens, J., Opipari, L., Nobile, C. \& Spirito, A. (1998) Sleep and daytime behavior in children with obstructive sleep apnea and behavioral sleep disorders. Pediatrics, 102, 1178-1184.

Parker, G. (1979) Parental characteristics in relation to depressive disorders. Br. J. Psychiatry, 134, 138-147.

Richman, N., Stevenson, J. \& Graham, P.J. (Eds.) (1982) Preschool to school: A behavioral study., Academic Press, London.

Roberts, R.E., Roberts, C.R. \& Chen, I.G. (2002) Impact of insomnia on future functioning of adolescents. J. Psychosom. Res., 53, 561-569.

Rosen, C.L., Storfer-Isser, A., Taylor, H.G., Kirchner, H.L., Emancipator, J.L. \& Redline, S. (2004) Increased behavioral morbidity in school-aged children with sleep-disordered breathing. Pediatrics, 114, 1640-1648.

Scher, A., Epstein, R., Sadeh, A., Tirosh, E. \& Lavie, P. (1992) Toddlers' sleep and temperament: reporting bias or a valid link? A research note. J. Child Psychol. Psychiatry, 33, 12491254

Stores, G. (1999) Children's sleep disorders: modern approaches, developmental effects, and children at special risk. Dev. Med. Child Neurol., 41, 568-573.

Yokomaku, A., Misao, K., Omoto, F., Yamagishi, R., Tanaka, K., Takada, K. \& Kohyama, J. (2008) A study of the association between sleep habits and problematic behaviors in preschool children. Chronobiol. Int., 25, 549-564. 